\title{
Versiones dramáticas, narrativa y metadrama en la obra de Abelardo Estorino
}

\author{
Alberto Rivera Vaca \\ Universidad de Tennessee, Estados Unidos \\ ariveravaca@gmail.com
}

Fecha de recepción: 25/09/2019. Fecha de aceptación: 22/01/2020.

\begin{abstract}
Resumen
Uno de los fundamentos de la poética de la literatura dramática de Abelardo Estorino (Cuba, 1925-2013) consiste en la precisión y fluidez de la palabra, y la renovación estilística. Escribe obras para ser leídas y no solamente representadas, pensando siempre en el lector además del espectador, pues es un contador de historias a través del modo dramático, y es la palabra exacta que impulsa la acción teatral. Asimismo, los textos dramáticos poseen innovaciones estilísticas como procedimientos narrativos modernos y manifestaciones metadramáticas. Estos recursos literarios se evidencian desde la transformación de los títulos de las obras, la relación entre los títulos y el texto dialogado y las correspondencias intertextuales e intratextuales. Principalmente, Estorino escribe para reflexionar sobre el fenómeno teatral, tiene una conciencia de sí mismo como dramaturgo para comprender el proceso de composición dramática.
\end{abstract}

Palabras clave: Dramaturgia, metadrama, poética, narrativa, géneros literarios, Estorino.

\section{Dramatic Versions, Narrative and Metadrama in the Work of Abelardo Estorino}

\begin{abstract}
One of the poetic foundations of the dramatic literature of Abelardo Estorino (Cuba, 1925-2013) consists on the precision and fluidity of the word, as well as on stylistic renovation. His works are written not only to be represented, but also to be read. He always thinks of the reader in addition to the spectator, since he is a storyteller through the dramatic mode, and it's the exact word what pushes the theatrical action forward. Also, the dramatic texts have stylistic innovations, like modern narrative procedures and metadramatic manifestations. These literary resources are evident in the transformation of the titles of the works, in the relationship between the titles and the dialogued text and in the intertextual and intratextual correspondence. It can be said that Estorino writes mainly to reflect upon the theatrical phenomenon:
\end{abstract}


his self-awareness as playwright allows him to understand the process of dramatic composition.

Keywords: Dramaturgy, metadrama, poetics, narrative, literary genres, Estorino

Ambicioso y renovador, un clásico en su propia tradición. Aspiró a ser grande, sin estar pendiente de lo que se hacía en Europa (Estorino, 2003: 6, 10). Las facetas de la obra dramática de Abelardo Estorino (Cuba, 1925-2013) son tan variadas como excepcionales. Los temas recurrentes de su trabajo abarcan el ambiente pueblerino y la familia como representaciones de la sociedad cubana, el machismo, la violencia, el racismo y el matrimonio (Pogolotti, 2012:7-8). El análisis de estos asuntos descubre las causas de los conflictos y contradicciones en la sociedad, o sea, busca la verdad; y en esta exploración revela cuestionamientos éticos y morales (Montero, 2004:13, 14). El evidente compromiso social de ideales factibles soslaya el arte panfletario (Montero, 2004:18) y la seducción de la palabrería de trinchera (Pogolotti, 2012:11). Con una conciencia histórica, indaga el presente y reflexiona sobre lo cubano, ejemplificando con sus primeras creaciones el teatro revolucionario (Lisenby, 2014:117, 118), discurriendo entre el pasado decimonónico y el contemporáneo, entre la etapa pre-revolucionaria y la Revolución Cubana, es decir, un teatro cubano de transición (Muñoz, 1986:39). Posee una obra que surge a lo largo de medio siglo con amplios cambios en Cuba, indagándolos, debatiéndolos, y reflexionando en cuanto a la función del teatro y el arte ante la sociedad (Pogolotti, 2012:11). Un teatro donde los cubanos se reconocen (Valiño, 2004:8) y examinan como sociedad, buscando cualidades propias y genuinas de su "identidad nacional" (Martínez-Tabares, 1996:47).

En cuanto a la técnica y los recursos dramáticos, las primeras obras de Estorino - Hay un muerto en la calle (1954), El peine y el espejo (1956) y El robo del cochino (1961)- pueden considerarse realistas de tono costumbrista (Escarpanter 199:881), desarrollando luego este método con más profundidad (Montero, 2004:19), adaptando en obras como Las impuras (1962), novelas que indagan la sociedad cubana. En un segundo momento, para Montero, Los mangos de Caín (1965) incurre en la abstracción y en proyectos más ambiciosos, diversificando sus procedimientos dramáticos y alcanzando, al mismo tiempo, sencillez e intensidad (Montero, 2004:13). De esta manera, como dice Estorino, va elaborando "un teatro imaginativo" sin abandonar el realismo (2003:6). En la década de los 80, continúa con la innovación de su teatro para repensar la historia en Morir del cuento (1983); en los 90 desafía la habitual forma de escribir teatro en Vagos rumores (1992), Parece blanca (1994) y El baile (1999) (Valiño, 2004:8). La estimulación que el dramaturgo provoca representa el carácter de gran madurez como autor (Montero, 2004:17). Igualmente, considero que con $N i$ un sí ni un no (1980), aumenta la cualidad metadramática, pues escribe literatura dramática para hablar del teatro y comprender la experiencia del dramaturgo en el proceso de producción de una obra.

Debido a la calidad e innovación de la obra de Estorino, se espera que continúe la producción de volúmenes de estudios críticos de amplio alcance sobre sus textos. En este artículo, me limitaré a la descripción y el análisis de los textos dramáticos (teatroliterario). Analizaré la transformación de los títulos de las obras, la relación entre estos y el texto dialogado y las correspondencias intertextuales e intratextuales. De esta manera, distinguiré tres tipos de textos dramáticos en la obra estoriniana: originales, versiones genéricas y versiones no genéricas. Luego, estudiaré la correlación de los textos dramáticos con las obras narrativas que retoma, identificando procedimientos narrativos modernos y manifestaciones metadramáticas en los textos dramáticos. Esto me conducirá a confirmar que la escritura, la palabra, es uno de los principales fundamentos de su concepción teatral. Estorino escribe literatura dramática para ser leída y no solamente para ser representada. Piensa en el lector además del espectador teatral, pues es un contador de historias a través del modo dramático. Recurriré a la 
terminología dramatológica como guía conceptual del fenómeno dramático, permitiendo de esta manera una descripción estructural de los textos dramáticos, procedimiento que posibilite verificar elementos constitutivos de la obra.

\section{Títulos y versiones}

Un texto dramático está compuesto por el diálogo y la acotación. La acotación es aquello que no es diálogo, como las indicaciones escénicas que aparecen insertas entre los diálogos, la lista de actores, las indicaciones temporales y espaciales, las descripciones del decorado, etc. Asimismo, un título es considerado también como una acotación y puede tener un subtítulo que describa el género, la estructura, el tema y el estilo de una obra (García-Barrientos, 2015:43). Un título pertenece al significado del texto que le sigue y concentra el mensaje entero que este contiene, además de preanunciarlo y remitirlo (Fernández- Martínez 2001:136). A continuación, me detendré en el análisis de los títulos (y los subtítulos) de la literatura dramática de Estorino, refiriéndome a estos como acotaciones, siendo el único tipo de acotaciones que tendré en cuenta en este análisis.

Desde un punto de vista cronológico, los títulos de los textos dramáticos de Estorino aumentan en complejidad semántica a la par del contenido del texto dialogado. Esto supone una ampliación del significado de estas acotaciones que pasan de ser informativas y convencionales a sugerentes y renovadoras. Los títulos se transforman en acotaciones metadramáticas, término utilizado por García-Barrientos al describir las acotaciones "que se refieren al drama en cuanto tal" (2015:47). En Estorino existe una progresiva intensificación en la relación entre el título y subtítulo con el texto dialogado, develando la voz, la actitud y el tono del autor. Según lo dicho, describiré tres tipos de textos dramáticos del dramaturgo cubano: originales, versiones genéricas y versiones no genéricas.

a) Textos originales. Las primeras obras dramáticas de Estorino son creaciones propias - esto es, no son adaptaciones ni versiones-y llevan títulos convencionales informativos que refieren a la estructura o género del texto dialogado: Hay un muerto en la calle. Un acto (1954), El peine y el espejo. Un acto (1956), El robo de cochino. Pieza en tres actos (1961). Las vacas gordas. Comedia musical (1962) o La casa vieja. Pieza en tres actos (1964). Estos títulos llevan una relación de identidad con los textos dialogados o concentran el contenido entero del mismo. El autor tituló estos textos dramáticos de un modo tradicional en la dramaturgia. Los subtítulos, a manera de acotaciones, informan al lector o guían al director y a los actores. Durante la década de los ochenta, el título de otras obras tendrá características similares: Ni un si ni un no. Comedia en dos actos (1980) o Las penas saben andar. Monólogo (1989). Todas las obras mencionadas con títulos informativos convencionales son creaciones dramáticas propias del dramaturgo.

b) Versiones genéricas. Si bien la mayor parte de la literatura dramática de Estorino está compuesta por textos originales, tiene asimismo varias obras que son versiones genéricas. Ha versionado dos novelas extranjeras y dos novelas cubanas, todas del siglo XIX; otra de comienzos del siglo XX y una novela mexicana de mediados del siglo pasado. La versión genérica es una obra dramática que se basa en una obra perteneciente a otro género. Los textos fuentes de algunas obras de Estorino remiten a géneros literarios como el cuento y la novela. Por ejemplo, la Cucarachita Martina yel Ratón Pérez (1961) es una versión del cuento de tradición popular del mismo nombre. La trama de este cuento popular, según Cuesta de Vélez, se identifica primeramente en una narración de la escritora española Fernán Caballlero (1796-1877). Fue reescrito y transformado en numerosas versiones en América por escritores como el venezolano 
Vicente Marcano, la costarricense María Isabel Carvajal Quesada (Carmen Lyra) o el venezolano Antonio Arráiz (2013:362-63). Los mangos de Cain (1965), por su parte, corresponde a este tipo de versiones, pues está compuesto por fragmentos y protagonistas bíblicos.

La adaptación genérica - que nombro en este trabajo versión genérica- es una "reescritura teatral (dramática y/o escénica) de un texto-fuente (teatral o no, en este caso narrativo) previo, reconocible y declarado, versión elaborada con la voluntad de aprovechar la entidad poética del texto fuente para implementar sobre ella cambios de diferente calidad y cantidad" (Dubatti, 2012:37). Sin dejar de considerar el sentido del término señalado por Dubatti, utilizo el término versión genérica y no adaptación genérica, porque varios de los subtítulos de la obra de Estorino explicitan que son versiones, no adaptaciones de obras narrativas. Pero, además, si bien la versión y la adaptación teatral pueden considerarse como sinónimos, la versión teatral modifica, mientras que la adaptación preserva (Apolo, 2010:35). Por ejemplo, una adaptación genérica de notable calidad que explicita en el subtítulo la relación con el texto fuente es la obra póstuma $E \cos y$ murmullos. Abelardo Estorino lee la novela de Juan Rulfo (2015), "una lectura bastante fiel a la novela de Rulfo, de por sí teatral y sintética" (Pino 2015:9), una forma de homenaje a Rulfo, a quien debió mucho, una manera de preservar recursos teatrales que Estorino consideró valiosos. En cambio, las versiones de Estorino transforman, reescriben el texto fuente, creando una segunda obra distanciada de la fuente original. Algunas muestras de estas versiones genéricas son las siguientes: El Mago de Oz. Versión de la historia de Frank L. Baum (1961), Las impuras. Versión de la novela de Miguel de Carrión (1962). La Dama de las Camelias. Versión para titeres $y$ actores de la novela de Alejandro Dumas (1968).

Las versiones genéricas de Estorino llevan títulos prestados y suponen un mecanismo de intertextualidad explícita que refiere obviamente a un texto externo. El autor se limita a informar, aunque anuncia las particularidades intertextuales de su obra. Existen versiones genéricas que no explicitan el término versión en los subtítulos, pero expresan la palabra novela. Estas acotaciones revelan los mecanismos estilísticos y las relaciones genéricas entre el texto dramático y sus fuentes, evidenciando la reflexión en cuanto a la relación entre la narrativa y la dramaturgia y las características metadramáticas de los títulos - como Parece blanca (1994), versión genérica de la novela Cecilia Valdés del cubano Cirilo Villaverde-, temas que trataré más adelante. Como bien reconoce Martínez-Tabares, el trabajo creativo de Estorino "se ha tratado de audaces rescrituras, alterativas y conscientes violadoras del canon, al apropiarse con entera libertad de la herencia y reconfigurarla a la luz de hechos y escenarios contextuales singulares" (2009:58).

La presencia de lo narrativo en las versiones genéricas de Estorino ha sido una necesidad temática más que experimental. De acuerdo con él, la intertextualidad "no ha sido una voluntad" exactamente consciente, sino "la necesidad de algo que decir", por ejemplo, "para crear la atmósfera del siglo XIX" en el caso de Parece blanca: "Entonces no es buscar la intertextualidad por la intertextualidad, sino que eso tiene un sentido para lo que estoy escribiendo" (Estorino, 2003:11-12).

En estas versiones genéricas de obras narrativas existen claramente distintos grados de alteración cualitativa. Los cambios de la poética son fundamentales "a causa de la transposición de los códigos de un género a otro. Los lenguajes de la novela [...] necesariamente son modificados por las reglas del discurso teatral, que en el texto dramático se articula en una doble enunciación: el discurso de las didascalias (enunciación inmediata) y el discurso de los personajes (enunciación mediata), según Anne Ubersfeld (1993)" (Dubatti, 2008:168). 
c) Versiones no genéricas. Según Dubatti, en la adaptación no genérica - que nombraré asimismo versión en lugar de adaptación como expliqué antes-, el texto fuente es un texto teatral y no hay cambio de género (2008:162). Además, este tipo de obras pueden llevar simplemente el nombre prestado de la fuente dramática original, y "no es la diferencia entre el original y su versión sino la profunda identidad entre ambos textos", pues esta preserva la trama, los hechos (Apolo, 2010:35). Los problemas de estas obras son de escala, el presente y la evocación, y el mundo interior, en otras palabras, la conciencia (Apolo, 2010:36-38). Existen tres textos dramáticos de Estorino, cuyas fuentes son obras teatrales o, según el dramaturgo, están inspiradas en estas: El tiempo de la plaga (1969) inspirada en Edipo rey de Sófocles; Pachencho vivo o muerto, basada en El velorio de Pachencho, de los hermanos Gustavo y Francisco Robreño (1982) y Medea sueña Corinto. Un monólogo imposible (2008).

No obstante, cabe señalar que Estorino, el escritor inconforme, reescribe y versiona igualmente sus textos originales (descritos anteriormente), perfeccionando y desarrollando la concepción que tiene del arte dramático. Por ejemplo, El robo del cochino (1961) es El peine y el espejo (1956) y, según el autor, El tiempo de la plaga (1968) fue reescrita en tres oportunidades y Los mangos de Cain (1965) es La casa vieja (1964), pero compuesta de distinta forma. Busca asimismo la abreviación, pues Vagos rumores (1992) es una versión reducida de La dolorosa historia del amor secreto de José Jacinto Milanés (1973). Estorino dice al respecto: "A mí me parece también que esa síntesis es lo que hay que lograr en el teatro" (2003:9). Este procedimiento sintético es fundamental en el proceso creativo del dramaturgo, no solamente para versionar obras narrativas y dramáticas, sino para hacer lo mismo con sus propios textos. Reescribir, versionar y sintetizar manifiestan la concepción teatral de Estorino: la dedicación a la palabra con el propósito de ser clara, comunicativa y significativa, concepción que viene de considerar el teatro como literatura, tema que desarrollaré posteriormente.

\section{Títulos metadramáticos}

Un título es una acotación; y una acotación genuina es muda e impersonal donde no habla nadie, a diferencia del texto dialogado donde dialogan los personajes (García-Barrientos, 2015:40). Contrariamente a esta definición, las acotaciones (títulos y subtítulos) de Estorino adquieren una distinción metadramática, donde además de mencionar el género, la estructura y estilo del texto, las acotaciones evidencian la voz del autor y la reflexión de este con respecto a la actividad dramaturga. Baste, como muestra: Que el diablo te acompañe. Vamos a decir comedia (1987). Parece blanca. Versión infiel de una novela sobre infidelidades (1994). Yo fumo Marlboro. Un acto muy corto, casi un suspiro (2002). Medea sueña Corinto. Un monólogo imposible (2008). En estas acotaciones las isotopías "vamos a decir", "parece", "infiel", "casi", etc., tienen un matiz de duda o indeterminación hasta alcanzar lo "imposible". La opinión del dramaturgo informa las características de los textos dramáticos, valorando así la obra. De esta manera aumenta la intertextualidad interna entre acotación y texto dialogado.

Analicemos uno de estos títulos metadramáticos. En Parece blanca. Versión infiel de una novela sobre infidelidades, tanto el título como el subtítulo refieren al contenido del texto fuente, la novela Cecilia Valdés de Villaverde y al texto dialogado. De aquí que esta acotación tiene dos relaciones textuales. La primera es una intertextualidad externa. La frase Parece blanca es una alusión literal que se halla en la tercera parte de la novela, donde el Dr. Montes de Oca pregunta a Josefa - la abuela afrocubana de Cecilia - por la nieta de esta: "qué tal parece la muchacha", a lo que Josefa contesta: "su figura y su parecer son los que van a acabar conmigo ... Parece blanca" (Villaverde y Lamore, 2000:339). El título del texto dramático es una alusión textual, pues no explicita la fuente y la identificación de la novela depende del conocimiento del lector. 
La segunda relación textual es una intertextualidad interna, la relación entre la acotación y el texto dialogado, conteniendo así una metareflexión. El título alude intertextualmente a la novela, pero el subtítulo describe la cualidad del texto dialogado: "Versión infiel de una novela sobre infidelidades". Estorino explicita más aún que su versión genérica traiciona al texto fuente. Este título resulta una parodia al estilo y propósito realista de la escritura de Villaverde, puesto que, en el prólogo de la segunda edición de la novela en 1882, Villaverde menciona la verosimilitud de la obra con respecto a la realidad social cubana de las primeras décadas del siglo XIX, describiéndola como "fiel pintura". Este afán le tomó cuarenta años para escribir y reescribir la novela. La parodia se extiende al estilo recatado de Villaverde, lo cual, contradictoriamente, lo haría inverosímil, pues el novelista declara: "nunca he creído que el escritor público, en el afán de parecer fiel y exacto pintor de las costumbres, haya de olvidar que le merecen respeto la virtud y la modestia del lector", pues una obra no puede ser "pintura impúdica o grosera" por ser verídico a la realidad (Villaverde y Schulman, 1981:7). Parece blanca, contiene algunos diálogos que no siguen el estilo recatado de Villaverde. Siguiendo el significado de la raíz para (de parodia), Estorino va junto, a lado de la novela cubana, versionándola; pero al mismo tiempo ironiza la pretensión de verosimilitud de la novela, traicionándola.

En otro ejemplo, el título metadramático Yo fumo Marlboro. Un acto muy corto, casi un suspiro compara la extensión del acto con algo menos que un suspiro, revelando el tono de humor del autor con respecto a su propia obra. Pero este título representa igualmente el contenido del texto dialogado y las características de los personajes. Pongamos por caso, el extranjero idealiza la Revolución Cubana: "Yo lo imaginaba todo, todo, como si lo hubiera vivido", y anhela: "Quiero verlo todo, entenderlo todo, vivir como viven ustedes" (Estorino, 2012:840, 843). Baby, activista cubana que reside en los Estados Unidos desde su niñez, recuerda su vida de pequeña en Cuba a través de fotos. Machi cree en la propaganda comercial, imagina fantasías y vive evocando su infancia antes que llegara la Revolución: "Absorbo el humo de un Marlboro y veo llanuras inacabables, caballos al trote, sombreros tejanos. Como los anuncios. Un mundo de aventuras" (2012:841). Las fantasías, idealismos y memorias de los personajes son semejantes al (casi) suspiro - aspiración prolongada seguida de una espiración-acompañado de expresiones que denotan pena, ansia o deseo. Machi también habla de lo más valioso que posee: "Tengo... tengo... (busca la palabra) el humo del Marlboro. ¡Sí! El humo. (Se va calmando.) El recuerdo de la finca de mi abuelo. Y el humo... Recuerdo también... recuerdo... el humo, el humo... el humo, el humo..." (2012:845). Fumar, como lo dice Machi, es una adicción que calma sus ansias. Este acto de aspiración y espiración es semejante al acto de suspirar que refiere el subtítulo. Las ilusiones, idealismos y memorias de los protagonistas son además parecidos al humo que se disuelve. Al contrario, Cuca, quien trabaja para Mechi y se identifica con la Revolución, parece ser más objetiva con respecto a la realidad, pues para ella, al final de cuentas, todo es trabajo. Yo fumo Marlboro retoma temas como socialismo, raza, migración y problemas generacionales discutidos vigorosamente en La casa vieja (1964).

\section{Sobre logocentrismo y escenocentrismo en Estorino}

Hasta el siglo XIX dominó la concepción logocéntrica que "considera la obra del 'poeta', el texto escrito, como el elemento primero, autónomo y principal del arte teatral" (García-Barrientos, 1991:25). Este pensamiento sigue vigente, aunque, la concepción escenocéntrica, consolidada durante el siglo XX, entiende el "espectáculo o puesta en escena como realidad primera, principal y autónoma". Pero ambas concepciones son "excluyentes en la medida en que uno y otro pretenden dar cuenta del teatro en 
su totalidad, atribuir la 'plenitud' al texto o a la escena" (García-Barrientos, 1991:2728). Debido a estas concepciones, el teatro es literatura para algunos y únicamente representación teatral para otros.

Veamos brevemente la manera en que el pensamiento y el quehacer teatral de Estorino se relacionan de alguna forma con el logocentrismo y el escenocentrismo. Previo a la composición de sus primeros textos, como todo dramaturgo destacado, Estorino recuerda: "yo había leído mucho teatro, había visto mucho teatro" (2003:6). En otra entrevista afirma: "He defendido siempre el teatro como literatura y me interesa cuidar mis textos tanto como cuida los suyos un poeta. Si no lo logro es una cuestión de incapacidad de mi parte. Pero un teatro sin un texto que fluye, que cante, que tenga un motivo, no es un teatro" (Valiño y Hernández-Lorenzo, 2013: s/p). Simplemente al analizar el proceso de transformación de las características semánticas de las acotaciones se evidencia que a Estorino le interesa el lector además del espectador. Este lector es comprensiblemente el director y los actores de sus obras de teatro, pero, además, el lector de literatura dramática. Escribe textos dramáticos no solamente para escenificarlos, sino para ser leídos. Elabora "un teatro disfrutable para el espectador y también para el lector" (Pogolotti, 2012:12). Por eso ha sido llamado "el literato de escritura resplandeciente" (Valiño, 2004:6). Estorino también ha dicho: "yo creo que siempre cuidé mi lenguaje para que tuviera poesía" (Lisenby, 2014:121). Sus obras aumentaron en calidad a la par de su empeño por perfeccionar la escritura de sus textos: "A partir de Milanés ha crecido mi lucha por hacer cristalino y expresivo al mismo proceso de creación" (Estorino, 2003:9).

Esta concepción del teatro como literatura y el cuidado en la escritura es producto de la lectura asidua. Estorino menciona repetidamente sobre la importancia de seguir el modelo de los más importantes dramaturgos y narradores, y leer todo en cuanto se pueda para escribir una obra. Confiesa que luego de escribir unas horas por las mañanas, se concentra en la lectura: "me dedico a leer, lo que me hace pensar continuamente en la obra que estoy escribiendo... Cualquier cosa que lea me sugiere una idea y todo me lleva al tema que estoy tratando en la obra"; por eso exige asimismo que el deber de los directores cubanos de teatro sea "leer y releer un bocadillo hasta descubrir exactamente lo que el autor quiso decir" (2003:12-13).

En efecto, hay quienes consideran que la literatura dramática "posee un doble destinatario": primero, el director, y segundo, el lector y analista; por tanto: "si el teatro es ante todo un arte de la representación, es también -precisamente a causa de esta características- un arte de la lectura" (Thomasseau, 1997:116-118). Para el dramaturgo argentino Abelardo Castillo (1935-2017), si bien los dramaturgos escriben un texto dramático con el propósito de ser teatralizado, hay textos dramáticos que pueden ser leídos como literatura sin la necesidad de ver su teatralización. Castillo cree que el teatro está muy ligado con el lenguaje: "Porque el teatro es palabra, más que acción visual" pues "el movimiento teatral se da en el diálogo", el "movimiento teatral es la palabra", y "la palabra hace mover la obra"; por eso, evoca Castillo, García Lorca "creía que el teatro era literatura y nada menos que literatura. Y el resto, lo que no era literatura, era circo" (Irazabal, 2010:5, 8).

Estorino explica lo siguiente con respecto a la estrecha relación entre teatro y literatura: "Los que se llaman literatos consideran que literatura es la narrativa y la poesía ... El teatro lo consideran un mundo aparte, de entretenimiento, en el cual la literatura no entra, cosa que me parece extraña porque, a veces, cuando están hablando de literatura citan a Shakespeare y no lo citan por los sonetos, lo citan por Hamlet o por Coroliano" (Valiño y Hernández-Lorenzo, 2013: s/p). Se puede afirmar que la concepción escenocentrista, instalada desde el siglo XX hasta esta época, predomina aún en algunos literatos pues suponen el teatro como puramente escénico y 
de entretenimiento. Esto tampoco quiere decir que aquellos tengan una concepción logocéntrica, ya que presumen únicamente a la narrativa y a la poesía (y habría que incluir al ensayo) como literatura y no así al texto dramático. Esta concepción de algunos juzga al teatro como escenificación poco seria y al texto dramático como insuficientemente literario. El teatro de Estorino recurre a procedimientos creativos modernos y renovadores, instaurados especialmente a partir del siglo XX, pero sin subsumir una concepción escenocéntrica del teatro, propia de aquel siglo. Debido a la importancia que Estorino da a su literatura dramática, se acerca más al logocentrismo, concepción más tradicional y convencional.

No obstante, si bien escribe para ser leído, lo hace para representar; por eso, su interés temprano en el teatro para niños, el teatro de títeres, o el teatro musical, como Las vacas gordas (1962), de afanoso montaje. Y a pesar que haya tenido que dirigir sus propias obras, como lo lamenta, siempre esperó que otros las dirigieran con el propósito de experimentar miradas distintas y encontrar nuevas posibilidades de aquello que había escrito (Estorino, 2003:12).

\section{Narrativa y dramaturgia}

La relación entre dramaturgia y narrativa es evidente y central en la obra de Estorino. Específicamente, esta es una relación entre la dramaturgia y la novela, y no así con el cuento. ${ }^{1}$ Según Estorino, parte del proceso de pre-escritura para la composición de sus textos literarios incluye la lectura reflexiva de la novela moderna además de la dramaturgia: "Los modelos que escojo son grandes cimas de la dramaturgia universal. No me conformo con menos de Sófocles, Shakespeare, Calderón, y si pienso en la novela tengo como guía a Proust o Rulfo. Joyce está más allá de mis posibilidades para saquearlo. Por lo tanto, el trabajo de pre-escritura es largo" (Martínez-Tabares y otros, 2002:22). Asimismo, afirma: "Yo, si estoy influido por algo, es más por la novela que por el teatro mismo... Eso me lleva también a ver el teatro como un texto literario, y entonces reviso continuamente: no hago una versión y me parece que ya basta con ella, sino que busco la forma de hacer ese texto más sintético, con más ritmo" (Calcines, 2007: s/p). El dramaturgo cubano Amado del Pino (1960-2017), estudiante de Estorino, cuenta que su maestro le dijo en una ocasión que "le debía mucho a Rulfo" y por eso Pino sostiene: "Lo narrativo alimenta, perfila, hasta ilumina buena parte de su obra... En su dramaturgia mayor es fácil reconocer un ciclo de fuerte presencia narrativa" (Pino 2015:6). Estorino reconoce: "En Vagos rumores los personajes hablan desde la muerte y ahí está la huella que Rulfo dejó en mí. Pensé que se me había ocurrido escribir esa obra sobre un poeta, como dictada por otro" (Geirola, 2014:101). De hecho, Estorino llevababa varios años escribiendo una novela que titularía El tren y por eso ha dicho: "Siempre digo que llevo dentro un novelista frustrado" (Calcines, 2007: s/p).

La obra dramática de Estorino contiene características singulares de la novela moderna. En su obra póstuma Ecos y murmullos en Comala, "dramatiza la novela mexicana Pedro Páramo que tanto ha influido en su dramaturgia" (Lisenby, 2014:117). Según Martínez-Tabares, en Parece blanca "se mueve en la cuerda de su pasión rulfiana, fiel deudor de la novela como género en cuanto a la posibilidad de libre juego con el tiempo y el espacio, una vieja pasión apuntada desde dos de sus grandes obras teatrales precedentes". Existe, asimismo, la influencia de otros novelistas contemporáneos. En palabras de Martínez-Tabares, Amado del Pino identifica que "Parece blanca puede compararse obviamente con La Loma del Ángel, la novela que 
Reinaldo Arenas publicara en 1987, por las coincidencias en el sentido del humor, la irreverencia y el afán de recontextualizar los personajes" (Martínez-Tabares, 1997:98).

La influencia de la narrativa en la obra de Estorino es una manifestación general de la renovación que tuvo el teatro en el siglo XX, puesto que el teatro tiene la capacidad de "ampliar sus propios límites", el "potencial de transgredir espacios genéricos y de construirse en una práctica de transversalidad estética" (Fernández-Chapo, 2010:18). No obstante, antes de continuar, es importante precisar que desde una perspectiva histórica, la novela temprana de los siglos XV y XVI recibió la influencia indirecta de la dramaturgia, adoptando técnicas como los diálogos, soliloquios y otros aspectos dramáticos (Fludernik, 2008:373-74). Igualmente, la Poética de Aristóteles es el punto de inicio para cualquier teoría narrativa (Richardson, 2007:142), ilustrando elementos claves de la narratología mediante el teatro griego. Y solo durante las últimas décadas del siglo pasado, la narratología comenzó a considerar el drama como un género narrativo puesto que, por ejemplo, tiene narradores homodiegéticos que se dirigen al público, narradores como protagonistas que hacen que las cosas sucedan (Fludernik, 208:355, 368).

Estorino, además de recurrir a la novela del siglo XIX y de principios del XX como fuente de contenidos temáticos, acude a la novela moderna, fuente de estrategias teatrales. En la novela moderna, elementos fantásticos suelen interrumpir el relato principal, causando a menudo cambios en el plano temporal. En Ecos y murmullos en Comala es evidente. Domina la anacronía, las secuencias temporales, prolepsis y analepsis, exigiendo al lector reordenar las secuencias para comprender lo que se cuenta. De manera semejante, en Morir del cuento "La historia está narrada y representada a saltos" (Martínez-Tabares, 1996:39). En El baile, el presente y el pasado de Nina se alternan a través de los recuerdos entrañables de la mujer, valiosos como las perlas de su collar. En las instrucciones iniciales para el director de esta obra, el dramaturgo pide recrear un ambiente onírico y el texto dialogado es un impulso para que los actores desplieguen su imaginación. Las didascalias que corresponden a la mujer pretenderían representar el pensamiento de la actriz mientras actúa, permitiendo al lector imaginar el pensamiento de esta. El otorgar libertad a los personajes es un procedimiento similar que Estorino ofrece a los actores cuando dirige una obra: "me gusta que los actores no tengan que hacer lo que yo les pido, sino que ellos- obviamente, poniéndonos de acuerdo-vayan encontrando cómo se mueven" (Geirola, 2014:98-99).

En la novela moderna, el narrador desaparece o disminuye su intervención; y el diálogo y el monólogo interior dominan. Para El baile, Estorino afirma haber utilizado "el fluir de la memoria, el monólogo interior ... de la novelística de principios del siglo XX" con el propósito de "hacer que la acción surgiera de los recuerdos y fantasías de la protagonista" (Martínez-Tabares y otros, 2002:23). Así como el narrador en la novela moderna disminuye su presencia, Estorino limita en sus textos dramáticos didascalias e instrucciones para escenificar el texto; $y$ en algunas obras estas son mínimas. Esto se debe también a los modelos dramáticos que retoma, como el teatro griego, donde las acotaciones están por poco ausentes; y la apropiación indirecta del diálogo y soliloquios del drama por la novela temprana del siglo XVI.

Más aún, en la novela moderna, el narrador disminuye su presencia mediante personajes homodiegéticos, rasgo evidente y central en la literatura dramática de Estorino, ya que varios de sus personajes son también narradores. Una manera singular de narrar es mediante la intertextualidad externa, como se verifica en Parece blanca, donde Nemesia, Isabel, Cecilia, Leonardo (en dos oportunidades) y Pimienta leen en seis ocasiones (Estorino, 2012:776, 779, 782, 785, 786 y 798) citas directas de la obra de Villaverde correspondientes al narrador de la novela (ver Villaverde y Lamore, 
2000:197, 232, 162, 333, 405 y 634). Algunas de estas se encuentran ligeramente modificadas o reducidas por Estorino para abreviar la extensión o para adaptar la expresión de Villaverde al fluir expresivo del texto dramático, pero en ninguna existe una transformación sustancial.

Otro ejemplo donde los personajes cuentan sus propias historias se verifica en Morir del cuento. Novela para representar (1983). La primera impresión del título refiere a la narrativa, pero la obra no tiene relaciones genéricas ni referencias intertextuales. El significado del término cuento tampoco apunta a una narración breve de ficción; se relaciona más bien con expresiones coloquiales como morir del susto, morir de la risa o con locuciones que dan noticia de un embuste o engaño como tener mucho cuento o vivir del cuento, frases cercanas al chisme o enredo. El subtítulo Novela para representar tampoco alude al género literario sino a una noticia o relato que cuenta eventos infortunados de infidelidad y suicidio para ser representados.

De manera semejante, Morir del cuento es simplemente el relato de un suceso: el suicidio de Tavito (Estorino, 2012:603). El texto dialogado es un relato aciago capaz de conmover: "Las cosas venían mal desde hacía tiempo" opina Adela, a lo que Antonia

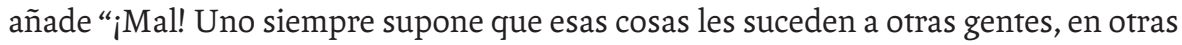
familias" (2012:601). En esta obra, según las instrucciones para el director, los personajes relatan y representan lo acontecido. Los "personajes narran la historia" desde la memoria, recuerdan y narran lo que saben: "yo contaré lo que sé, lo que recuerdo" además de "representar esa historia" (2012:596). Debido a esta multiplicidad de narradores que dialogan, un mismo acontecimiento es representado desde diversos puntos de vista, como sucede en la novela moderna.

Por lo expuesto, se puede considerar a Estorino como un contador de historias a través del texto dialogado, es decir, mediante los personajes. Se puede estudiar su dramaturgia literaria como narrativa, además de dramática. En entrevistas y opiniones, se evidencia que Estorino utiliza reiteradamente el término "contar" para hablar del teatro: "Escribir teatro consiste en encontrar la forma de expresar una idea o contar una historia mediante el diálogo de varios personajes" (Martínez-Tabares y otros, 2002:21, el énfasis es mío). Para El diablo que te acompañe, Estorino explica: "hice una estructura que me sirviera para contar muy bien la anécdota como una comedia de enredos" (2003:9-10). Y en relación a La casa vieja, afirma que los personajes "quieren contar sus problemas en público (aunque temen hacerlo)" (2003:7, el énfasis es mío). Estorino considera el teatro como una forma de contar a través de sus personajes además de un modo de representar.

\section{Metadrama para comprender la dramaturgia}

Los personajes que son narradores homodiegéticos en obras dramáticas, suelen manifestar rasgos metadramáticos (Fludernik, 2008:370). Este recurso permite a Estorino reflexionar con respecto a la creación dramatúrgica:

Desde 1980, con Ni un sí ni un no, el teatro me interesa no sólo para usarlo como medio expresivo, sino también como tema en sí de las obras que escribo. Necesito entender cómo la imaginación crea la obra, de dónde surgen los personajes, cómo se comportan y he descubierto que eso conlleva un conflicto y por lo tanto resulta un material dramatizable. De una u otra manera las piezas escritas después de esa fecha juegan con ese recurso que han llamado teatro dentro del teatro (MartínezTabares y otros, 2002:23). 
Antes de continuar con la explicación de la poética del texto dramático de Estorino, es oportuno aquí revisar y distinguir brevemente algunos términos como teatro dentro del teatro, metadrama y metateatro. García-Barrientos llama metadrama al teatro dentro del teatro, donde el actor se encuentra en "el plano real de la escenificación" o nivel extradramático; y "el personaje representado por el actor" se encuentra en el "plano de la ficción primaria" o nivel (intra)dramático. García-Barrientos denomina nivel metadramático cuando en el plano de la ficción existe un segundo, tercero o más grados, "lo que implica personajes representados por otros personajes, esto es, 'teatro dentro del teatro' en el grado que sea". Ahora bien, según García-Barrientos, no se debe confundir metateatro, "una escenificación dentro de otra", con metadrama, "un concepto más amplio, que incluye al anterior y que lo excede cuando el drama secundario no se presenta como resultado de una escenificación" (García-Barrientos, 2012:40-41). Cabe notar que Lionel Abel introduce el término metateatro en la década de los sesenta y explica que las obras de este género son aquellas donde el dramaturgo tiene una conciencia de sí mismo como tal y los protagonistas tienen una conciencia de sí mismos como personajes dramáticos $(1963: 77){ }^{2}$

Estorino reflexiona en cuanto al teatro, tiene una conciencia de sí mismo como dramaturgo y busca comprender el proceso de composición de una obra. Estorino señala: "Pirandelliano, dicen, cuando quieren clasificarme y en realidad partí de Brecht, al considerar el escenario sólo como eso: el escenario, y no la ilusión de un lugar real, donde contaremos una historia de ficción que nos ayudará, tal vez, a conocernos un poco más" (Martínez-Tabares y otros, 2002:23). Y también asegura: "Por eso he usado el recurso del teatro dentro del teatro, para evitar la ilusión" (Estorino, 2003:11). En Ni un síni un no se verifica aquello en las instrucciones para el director de la obra, y las constantes referencias a la misma y a los actores en el texto dialogado. En las explicaciones iniciales para la puesta en escena se lee: "La yuxtaposición de distintos elementos, unos realizados específicamente para la obra y otros ajenos a ella crearán ese efecto poético de ensayo y teatralidad que el autor se propone". Y para continuar con el desvanecimiento de la ilusión del escenario como un lugar real, instruye: "Los actores prepararán las escenas y se vestirán frente al público cuando sea necesario. El cambio de actor a personaje ocurrirá de forma que sea visible el proceso en que el personaje empieza a surgir" (Estorino, 2012:468).

Parece blanca ilustra singularmente otros aspectos metadramáticos. Los personajes teatrales representan protagonistas de la novela Cecilia de Villaverde, y son conscientes de aquello. Es decir, esta estrategia metadramática es la conciencia del personaje a la potencia o la conciencia de este en un plano de ficción secundario, y Estorino lo denomina personaje de ficción: "En Parece blanca, los personajes de la novela representan sus conflictos sabiéndose personajes de ficción e incapaces de cambiar lo que el novelista ha considerado su destino" (Martínez-Tabares y otros, 2002:23). Los personajes reconocen que son una adaptación de un texto de otro género literario, ganan libertad y se rebelan para escapar de su destino a pesar de que se halle determinado. ${ }^{3}$ Parece blanca es una creación donde el dramaturgo es responsable de todo para evadir la ilusión dramática. En su obra es posible encontrar una variedad de estrategias inusitadas como las descritas que expanden las posibilidades del recurso metadramático.

2 Abel sostiene: "Yet the plays I am pointing at do have a common character: all of them are theatre pieces about life seen as already theatricalized. By this I mean that the persons appearing on the stage in these plays are there not simply because they were caught by the playwright in dramatic postures as a camara might catch them, but because they themselves knew they were dramatic before the playwright took note of them" (1963:60).

3 El dramaturgo argentino Jorge Accame asevera: "en el teatro los personajes ganan libertad. Ya no son tan subsidiarios de mí, no están ligados al autor". Luego explica: “El uso de la ficción es, pues, un recurso consciente reconocido por el dramaturgo como una válvula de escape para sus personajes que, atendiendo a motivaciones diversas, sienten la necesidad de huir de la realidad que les ha tocado vivir" (Rodríguez-Solas, 2012:63). 


\section{Conclusiones: perfección y libertad}

Sustentado en que "nada permanece estático", Estorino es perfeccionista: "Creo que es necesario perfeccionar la vida, perfeccionarse uno, alcanzar cimas muy altas, soñar con la utopía"; y esto lo estimula a tener ambición por innovar y renovarse simultáneamente, otorgándole "libertad de creación", en sus palabras, independencia para expresar "las cosas que quiero decir, con la mayor libertad posible" $(2003: 13,12)$. Al mismo tiempo, Estorino es guardián de la premisa martiana: injerta en su teatro ideas del "mundo"; pero el "tronco" es lo provincial y la tradición cubana (y por qué no, americana).

En cuanto a sus textos originales, cada nueva obra es una extensión mejorada de otra anterior. Realiza versiones no genéricas de sus propias obras. De aquí que cada momento de su carrera dramática se destaca por sí misma en calidad; aun así, ninguna le satisfice. Algunas versiones genéricas de novelas fundamentales manifiestan su impulso de excelso lector: releer, versionar, reescribir, perfeccionar, porque todo es susceptible al cambio. Otras versiones genéricas rinden homenaje infiel a las fuentes narrativas que las originan. La voz del autor se evidencia desde los títulos, ávido por comunicar, mediante referencias intertextuales y metadramáticas.

Estorino no es un experimentador lúdico que alcanza el reconocimiento fortuitamente, se afana por la perfección para contar lo que anhela; lo narrativo en su dramaturgia es una necesidad, no un juego, ya que, para él, la escritura es oficio responsable y ético. Vigila el lenguaje, busca la palabra cristalina, fluida y sintética en cada diálogo. Custodia el teatro como literatura, respetuoso de su lector; para que luego, la palabra poética detone la acción sobre las tablas frente a su público. Su obra ejemplifica el arte de la lectura, escritura y representación. Dramaturgo moderno, pero libre del escenocentrismo, y si bien considera el texto escrito como algo principal, escribe para representar aquello que tiene por contar.

Estorino nutre su obra con la novela moderna en beneficio, principalmente, del contenido de su literatura, y luego, por los recursos estéticos que la novela ofrece, pues conoce de la libertad que da el teatro para transgredir géneros y aplicar procedimientos nuevos. De la novela moderna aprovecha lo fantástico, la alteración de la vectorialidad del relato principal, y la disipación del narrador. Cede a los personajes la responsabilidad de contar, y esta concesión les otorga libertad y consciencia del rol que tienen como personajes en la obra. Así indaga con respecto a los procedimientos involucrados en la creación, celebrando la reflexión metadramática. Ambicioso renovador, adverso a lo convencional, explora junto a sus personajes temas con toda libertad. 


\section{Bibliografía}

» Abel, L. (1963). Metatheatre: A New View of Dramatic Form. New York: Hill and Wang.

"Apolo, l. (2010). "Versión y adaptación teatral: de la narrativa a la dramaturgia”. Cuadernos de Picadero 19, 34-39.

"Calcines, A. (2007). "Hay que saber sobre Abelardo Estorino. Entrevista para representar”. Opus Habana 10 (2), 16-25, [en línea]. Consultado el 10 de mayo de 2018 en http://www.opushabana.cu/index.php/entrevistas/41-entrevistascp/689-hay-que-saber-sobre-abelardo-estorino-entrevista-para-representar-

» Cuesta de Vélez, C. (2013). "La travesía de la Cucarachita Martínez y el Ratón Pérez". Educere 17 (57), 361-367.

»Dubatti, J. (2012). “Jorge Accame: Intratextualidad, multiperspectivismo y complementariedad entre narrativa y teatro". En Wendorff A., Carlos D. y José G. (comp.), La narrativa en el teatro / El teatro en la narrativa: (convergencias transgenéricas en la literatura hispánica actual). (pp. 35-42). Lublin: La Campana Sumergida Editorial.

"Dubatti, J. (2008). Cartografía teatral: introducción al teatro comparado. Buenos Aires: ATUEL.

»Escarpanter, J. (1990). “Tres dramaturgos del inicio revolucionario: Abelardo Estorino, Antón Arrufat y José Triana”. Revista Iberoamericana 56 (152-153), 881886.

»Estorino, A. (2015). Ecos y murmullos en Comala. La Habana: Alarcos.

»Estorino, A. (2012). Teatro completo. La Habana: Alarcos

»Estorino, A. (2004). Teatro escogido. Omar Valiño (comp.). La Habana: Letras Cubanas.

" Estorino, A. (2003). "El dramaturgo en primera persona”. Encuentro de la Cultura Cubana 26-27, 5-13.

»Fernández-Chapo, G. (2010). “Literatura/Teatro: la deslimitación de las fronteras genéricas en el campo teatral argentino”. Cuadernos de Picadero 19, 17-22.

" Fernández-Martínez, J. (2001). La Intertextualidad Literaria: (base teórica y práctica textual). Madrid: Cátedra.

» García-Barrientos, J. (2015). Cómo se comenta una obra de teatro. Ensayo de método. La Habana: Alarcos.

"García-Barrientos, J. (2012). Análisis de la dramaturgia cubana actual. La Habana: Alarcos.

" García-Barrientos, J. (1991). Drama y tiempo. Madrid: Consejo Superior de Investigaciones Científicas.

» Geirola, G. (2014). Arte y oficio del director teatral en América Latina: Caribe: Cuba, Puerto Rico y República Dominicana. Buenos Aires: Argus-a.

"Irazabal, F. (2010). “El teatro como impulso". Cuadernos de Picadero 19, 4-10.

»Lisenby, D. (2014). "Con pluma de ganso revolucionario: Entrevista a Abelardo Estorino”. Latin American Theatre Review 47 (2), 117-122. 
» Martínez-Tabares, V. (2009). “Estorino sueña otra Medea americana”. Conjunto 150, 58-61.

"Martínez-Tabares, V. (1997). "Parece blanca: una relectura de Cecilia Valdés desde el teatro cubano". En Campuzano L. (ed.), Mujeres Latinoamericanas: Historia y cultura: Siglos XVI al XIX. (pp. 97-104). La Habana: Casa de las Américas.

"Martínez-Tabares, V. (1996). Didascalias urgentes de una espectadora interesada: aproximaciones al teatro cubano de hoy. La Habana: Editorial Letras Cubanas.

» Martínez-Tabares, V., Raquel Carrió, Flora Lauten, Cristóbal Peláez, Raúl Martín, Waddys Jáquez, Teresa Ralli, Abelardo Estorino, César Brie, Radhamés Polanco, Alejandro Aguilar, Gonzalo Callejas, Nara Mansur y Dinorah Pérez (2002). "Dramaturgias posibles en la América Latina y el Caribe". Conjunto 125, 12-29.

"Fludernik, M. (2008). "Narrative and Drama”. En Pier J. y Landa J. A. Theorizing Narrativity (pp. 355-383). New York: Walter de Gruyter.

"Montero, R. (2004). “Manera de ser Sófocles”. En Estorino A., Teatro escogido. (pp. 11-31). La Habana: Letras Cubanas.

» Muñoz, E. (1986). “Teatro cubano de transición (1958-1964): Piñera y Estorino”. Latin American Theatre Review 19 (2), 39-44.

»Pier, John, y Landa J. A. (2011). Theorizing Narrativity. New York: Walter de Gruyter.

" Pino, A. (2015). “Versión fiel de una pasión permanente”. En Ecos y murmullos en Comala. Abelardo Estorino, Alarcos, 5-10.

»Pogolotti, G. (2012). “Una educación sentimental”. En Estorino A., Teatro completo. (pp. 7-12). La Habana: Alarcos.

" Richardson, B. (2007). "Drama and narrative". The Cambridge Companion to Narrative. University Press, 142-155.

" Rodríguez-Solas, D. (2012). "La teatralización de la escritura en El chico de la última fila, de Juan Mayorga”. En Wendorff A., Carlos D. y José G. (comp), La narrativa en el teatro / El teatro en la narrativa: (convergencias transgenéricas en la literatura hispánica actual). (pp. 63-78). Lublin: La Campana Sumergida Editorial

» Thomasseau, J. (1997). “Para un análisis del para-texto teatral”. En Bobes M. (comp), Teoría del teatro. (pp. 83-118). Madrid: Arco/Libros.

»Valiño, O. (2004). “Pórtico”. En Estorino A., Teatro escogido. (pp. 7-9). La Habana: Letras Cubanas.

"Valiño, O. y Maité Hernández-Lorenzo (2013). "Yo soy el otro... y escribo teatro". La Jiribilla, 612, [en línea]. Consultado el 20 de febrero de 2018 en http://www. epoca2.lajiribilla.cu/articulo/3218/yo-soy-el-otro-y-escribo-teatro

»Villaverde, C. y Jean Lamore (2000). Cecilia Valdés o La Loma del Ángel. Madrid: Cátedra.

"Villaverde, C. e Iván A. Schulman (1981). Cecilia Valdés. Venezuela: Biblioteca Ayacucho. 